\title{
Los límites del ver: una aproximación a la pintura contemporánea
}

\section{The limits of seeing: an approach to contemporary painting}

\author{
TIPO DE TRABAJO: Comunicación. \\ PALABRAS CLAVE \\ Pintura contemporánea, imagen, visibilidad, invisibilidad, tiempo, negatividad.
}

KEY WORDS

Contemporary painting, picture, visibility, invisibility, time, negativity.

RESUMEN

\begin{abstract}
La ponencia que presentamos plantea una reflexión sobre las posibilidades expresivas del lenguaje pictórico y sus consecuencias en el proceso del ver. Para abordar esta cuestión, analizaremos el trabajo de Javier Garcerá (coautor de este artículo) que, frente a la proliferación de la información visual de naturaleza exhibicionista que nos afecta día a día, utiliza una serie de estrategias formales basadas en una cierta negación de la imagen y obstaculización de la mirada. En concreto, partiremos del proyecto expositivo titulado "Ni decir" (2018), el cual pretende estimular una apertura de la percepción que permita ver más allá de la representación pictórica, e incluso de cualquier imagen. Hecho que suscita una reflexión necesaria en el contexto imagen [n] visible que la presente edición del congreso ANIAV propone.
\end{abstract}

Para ello, nos serviremos de algunas reflexiones que el filósofo y teórico cultural coreano Byung-Chul Han está elaborando sobre el fenómeno de transparencia y exceso de visibilidad al que está expuesto el sujeto contemporáneo. Así también, aludiremos a otras ideas que autores como Walter Benjamin, Roland Barthes, Gilles Deleuze o Jean Baudrillard han planteado sobre dicho problema. Pretendemos así elaborar una aproximación al tema de la imagen [ $n$ ] visible desde una perspectiva que reflexiona en torno a los límites entre visibilidad e invisibilidad.

\section{ABSTRACT}

The paper that we present proposes a reflection on the expressive possibilities of pictorial language and its consequences in the process of seeing. To address this issue, we will analyze the work of Javier Garcerá (co-author of this article) who, faced with the proliferation of visual information of an exhibitionist nature that affects us day-to-day, uses a series of formal strategies based on a certain denial of the image and hindering of the look. Specifically, we will start from an analysis of the exhibition project entitled "Ni decir" (2018), which aims to stimulate an opening of perception that allows us to see beyond the pictorial representation, and even of any image. Fact that provokes a necessary reflection in the context imagen [n] visible that the present edition of the ANIAV congress proposes.

In order to attain that, we will use some reflections that the philosopher and Korean cultural theorist Byung-Chul Han is elaborating on the phenomenon of transparency and excess of visibility to which the contemporary subject is exposed. Also, we will refer to other ideas that authors like Walter Benjamin, Roland Barthes, Gilles Deleuze and Jean Baudrillard have raised about this problem. Thus, we intend to elaborate an approach to the subject of the imagen [n] visible from a perspective that reflects on the limits between visibility and invisibility. 


\section{INTRODUCCIÓN}

Si los medios digitales nos están facilitando el acceso ilimitado a cualquier tipo de información o de servicio que necesitemos de forma inmediata o la posibilidad de interconectar con otras personas de cualquier lugar del mundo, es también cierto que cada vez existe una mayor presión de producción, comunicación y consumo bajo ese incierto poder de libertad que nos ofrecen. El sujeto contemporáneo está sometido cada vez más a una pérdida de su intimidad, a un exceso de información y de actividad que ha dado lugar a un fenómeno de agotamiento, de inquietud y de asfixia.

El filósofo y teórico cultural coreano Byung-Chul Han señala en una entrevista publicada este año por el periódico El Mundo que el nivel de consumo mediático ha conducido a un "visionado bulímico", es decir, el sujeto "se apresura de una información a la siguiente, de una sensación a la siguiente, sin llegar nunca a un final" (Martinez, 2019). Según el filósofo, se ha producido una disminución de la capacidad perceptiva y analítica debido a la continua profusión de información visual y de estímulos al que está expuesto el individuo, lo cual dificulta esa atención sosegada que el autor considera vital para el desarrollo del conocimiento humano. No obstante, Han apunta que esa disminución de la capacidad perceptiva y analítica no es consecuencia exclusivamente del exceso de información visual, también se debe al carácter exhibicionista de tal exceso. En relación a ello, el autor indica en La sociedad de la transparencia que las imágenes mediáticas ofrecen un lenguaje carente de misterio y de ambigüedad, por lo que no logran captar nuestra atención durante mucho tiempo.

Considerando este contexto, en este estudio proponemos una reflexión sobre las posibilidades expresivas del lenguaje pictórico en relación al contexto social y cultural contemporáneo. Entendemos que en una sociedad saturada de imágenes como la nuestra se requiere un debate sobre el impacto de dichas imágenes desde una perspectiva que reflexione en torno a la experiencia del ver y sus consecuencias vitales. Frente a la transparencia y exceso de visibilidad al que está expuesto el individuo contemporáneo, la pintura se plantea aquí como alternativa que permite la intimidad, la reflexión y la demora.

Así, el estudio se va a centrar en el proyecto expositivo titulado "Ni decir" de Javier Garcerá, coautor de este artículo, el cual fue presentado en el Hospital Real de Granada en el año 2018 (Figura 1 y 2). Las obras pictóricas que componían dicha propuesta, la mayoría de grandes formatos que envolvían literalmente al espectador, están trabajadas a través de una serie de estrategias formales basadas en una cierta negación de la imagen y obstaculización de la mirada cuyo objetivo es estimular al espectador a experimentar un proceso de intensificación de la percepción. Para llevar a cabo esta pretensión, el coautor de este artículo ejecuta sus piezas prestando atención a la elaboración minuciosa de las características físicas del trabajo, reivindicando la manualidad y el oficio como modo de recuperar una significación que se apoya en la sensualidad de la materia.

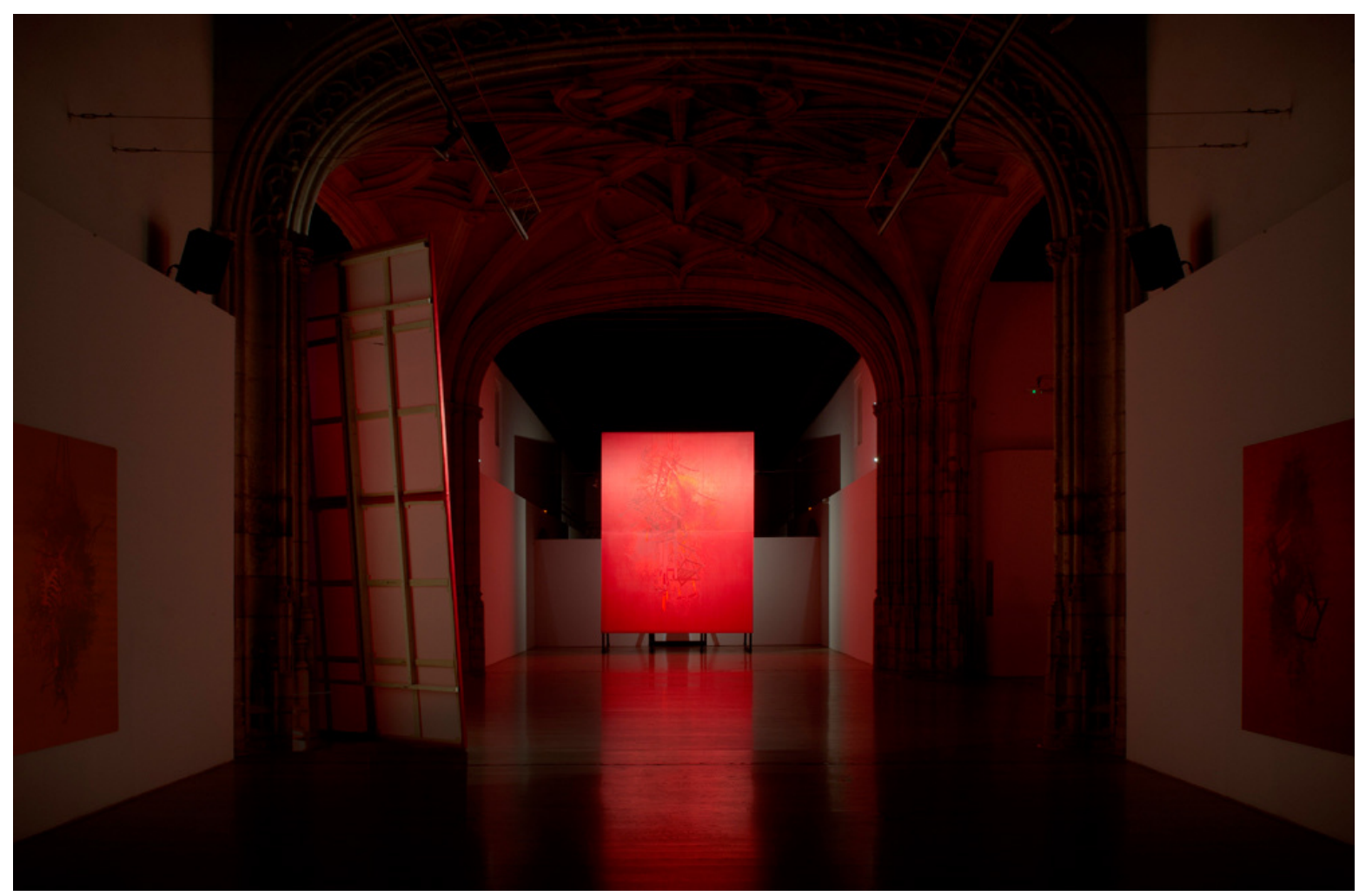

Figura 1. Vista de la exposición “Ni decir” de Javier Garcerá en el Hospital Real de Granada (España), 2018 


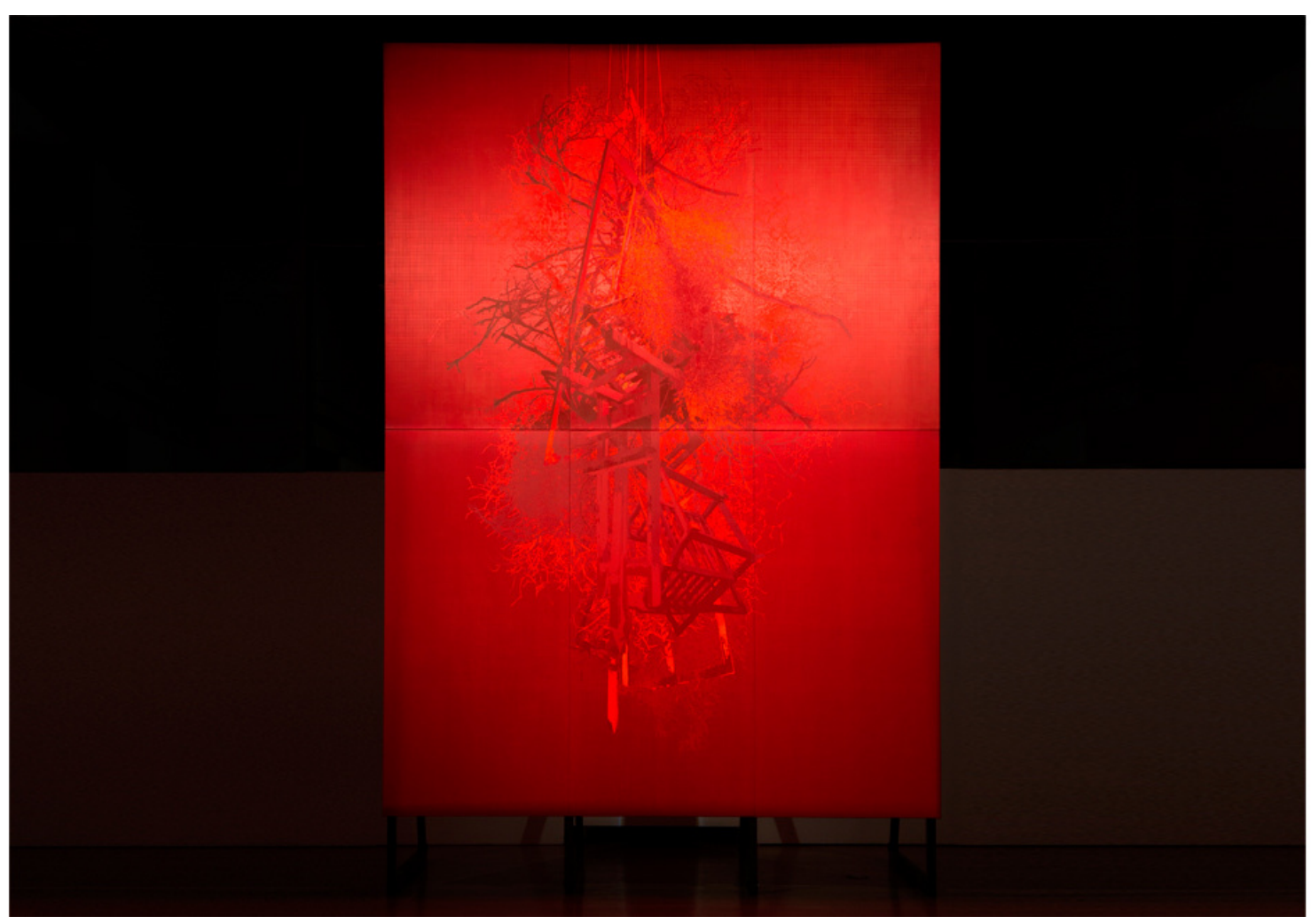

Figura 2. Javier Garcerá, “Que no cabe en la cabeza”. 500 x 360 cm., técnica mixta sobre seda, 2017

\section{DESARROLLO}

\section{Transparencia y exceso de visibilidad}

El fenómeno de transparencia está cada vez más presente en los diversos campos de actuación del ser humano; podemos percibirlo tanto en el ámbito político y económico como en las interacciones que el individuo realiza a través de los medios de comunicación. Pero no se limita sólo a dichos ámbitos pues, en palabras de Byung-Chul Han, el fenómeno de transparencia es "una coacción sistémica que se apodera de todos los sucesos sociales y los somete a un profundo cambio" (Han, 2013, p. 12). Según el filósofo, la coacción de la transparencia se basa en suprimir cualquier tipo de alteridad, anulando toda posibilidad de negatividad de lo otro y de lo extraño, con el fin de acelerar los ciclos de la información, la comunicación y la producción (Han, 2013).

Uno de los aspectos que define a la sociedad contemporánea y que se vincula a esa coacción de la transparencia es el exceso de visibilidad al que está expuesto el individuo. Han señala que "en la sociedad expuesta, cada sujeto es su propio objeto de publicidad. Todo se mide en su valor de exposición" (Han, 2013, p. 29). Se trata de un cambio de paradigma que ya Walter Benjamin reconoció hace más de ochenta años en su estudio La obra de arte en la época de su reproductibilidad técnica respecto al predominio que había adquirido el valor de exhibición sobre el valor de culto de una obra de arte como consecuencia del desarrollo tecnológico. En la década actual, se ha producido una absolutización de ese valor de exhibición, ya no se limita al ámbito artístico sino que está presente en todas las esferas de la vida cotidiana. Frente a la esencia en sí de la existencia, ahora "las cosas, convertidas en mercancía, han de exponerse para ser" (Han, 2013, p. 25). De acuerdo con esto, el fenómeno de transparencia se opone a todo aquello que queda oculto a la mirada, a lo que no es accesible y que, por tanto, no puede ser comprendido ni comunicado, pues supone un obstáculo para los círculos acelerados de la comunicación y la información.

Atendiendo a nuestro objeto de estudio, quisiéramos abordar a continuación una reflexión en torno a ese fenómeno de transparencia y exceso de visibilidad en el ámbito de los medios de comunicación digitales. En concreto, prestaremos especial atención al prototipo de imagen mediática con el fin de observar cómo dicho fenómeno está afectando tanto a la percepción como al conocimiento del sujeto contemporáneo.

La mayoría de las imágenes mediáticas que recibimos a través de los medios digitales están sometidas al valor de exhibición; carecen de esa negatividad que se vincula con los conceptos de lo oculto, lo misterioso y lo inaccesible. Según Jean Baudrillard, es obscena "toda forma que se fija en su aparición, que pierde la ambigüedad de la ausencia para agotarse en una visibilidad exacerbada" 
(Baudrillard, 1984, p. 57). El exceso de visibilidad es obsceno porque anula la capacidad de seducción, hace que todo esté "entregado, desnudo, sin secreto, a la devoración inmediata" (Baudrillard, 1984, p. 62). Esta idea se relacionaría con aquella que ya planteó Jorge Simmel y que hacía referencia al encanto de lo ignoto frente al conocimiento absoluto de algo. Simmel consideraba que "penetrar claramente hasta el fondo último de algo, es destruir su encanto y detener la fantasía en su tejido de posibilidades" (Simmel, 1927, p. 121). Siguiendo este planteamiento, consideramos que la falta de ambigüedad y de misterio de las imágenes mediáticas anula toda fantasía que desencadenaría una reflexión en el sujeto y posibilita la aceleración del proceso de percepción que requiere el sistema de consumo.

La exhaustiva visibilidad de una imagen anula toda distancia. Según Han, "a la sociedad de la transparencia toda distancia le parece una negatividad que hay que eliminar; constituye un obstáculo para la aceleración de los ciclos de la comunicación y del capital" (Han, 2013, p. 32). La falta de distancia es la proximidad absoluta de la cosa vista, pero no se debe confundir con el concepto de cercanía pues, como señala el filósofo coreano, "la cercanía es rica en espacio, mientras que la falta de distancia lo aniquila" (Han, 2013, p. 33). En este sentido, recordemos que Baudrillard ya reconoció a finales del XX que "los media no son una escena, un espacio con perspectiva, en la que se interpreta algo, sino una pantalla sin profundidad" (Baudrillard, 1984, p. 68). En relación a ello, Baudrillard señalaba que "nos acercamos infinitamente a la superficie de la pantalla, nuestros ojos están como diseminados en la imagen. Ya no tenemos la distancia del espectador en relación a la escena (...)" (Baudrillard 1991, p. 62). De acuerdo con esto, podemos señalar que la exhaustiva visibilidad de la imagen mediática digital anularía la mirada, pues carece de toda distancia necesaria para la reflexión y la contemplación estética.

\section{El don de estar a la escucha}

Si anteriormente hemos señalado que el fenómeno de transparencia favorece la aceleración de los ciclos de la información, la comunicación y la producción, es preciso destacar que esto es posible porque la sociedad contemporánea vacía de sentido toda acción social para convertirla en uniforme e insertarla en el rápido procesamiento que requiere el sistema de consumo. Así, la coacción de la transparencia, despojando de singularidad y de significación cualquier tipo de acción, fomenta la producción de sucesos que son aditivos. Según Han, "solo puede acelerarse un proceso que es aditivo y no narrativo", pues éste se encuentra inserto en su propio tiempo y ritmo de creación simbólica (Han, 2013, p. 60). En relación a ello, el filósofo reconoce en La sociedad de la transparencia que la crisis temporal que experimenta la sociedad contemporánea no es propiamente la aceleración, sino la dispersión y la disociación temporal. Se ha producido una desnarrativización del mundo que dificulta la reflexión sosegada y que refuerza la sensación de fugacidad.

De acuerdo con este planteamiento, consideramos que dicha situación ha propiciado que cada vez más artistas se interesen por un proceso de creación lento y pausado, atendiendo a los ritmos en los que la obra se desarrolla. En concreto, hemos podido percibir una revalorización de la labor artesanal del medio pictórico que, frente a esa percepción fragmentada y dispersa que posee el individuo contemporáneo, permite al artista permanecer en una actitud de escucha que tiene su origen en un vaciamiento y en una entrega a la infinitud del instante. Nos estamos refiriendo a ese don de estar a la escucha que Benjamin señalaba en su texto El Narrador y que, según el autor, requiere de un estado de relajación, es decir, sólo es posible cuando el sujeto se vacía de sí mismo y se sumerge en el ritmo de su trabajo. En este sentido, Javier Garcerá, coautor de este artículo, recupera esa capacidad de una intensa y contemplativa atención que Byung-Chul Han echa en falta en la sociedad contemporánea y que, como indica el filósofo en La sociedad del cansancio, es vital para la experiencia del ver.

Los cuadros de Javier Garcerá están realizados a través de una minuciosa atención y de un diálogo con el ritmo potencial de la materia que invita al espectador a experimentar una relación especular entre el tempo del hacer y del observar. Si nos centramos en el proyecto expositivo "Ni decir" del coautor de este artículo, observaremos que las piezas pictóricas que componen dicha propuesta están elaboradas a través de una complejidad formal de elementos visuales que invita a una percepción desde códigos de variación que invalida cualquier previsión intelectual e induce al espectador a la demora y a la contemplación (Figura 3). Como indica Juan Bta. Peiró, comisario del proyecto, en su texto escrito para el catálogo: "esta exposición apela a la experiencia individual del espectador, (...) para que pare el tiempo y se deje llevar con todas sus consecuencias por este espacio vital que trasciende los límites de la racionalidad" (Garcerá, 2018, pp. 9-10). Son obras que hacen visible su ritmo, frente al cual la voluntad del espectador se minimiza hasta retirarse, engendrándose así un estado en el que el tiempo parece paralizarse. Esta quietud es la que permite al espectador experimentar un proceso de intensificación de la percepción, al cual no es posible acceder frente a la proliferación de la información visual de naturaleza exhibicionista y las lecturas superficiales y narcisistas a las que invita la aceleración de la sociedad contemporánea. 


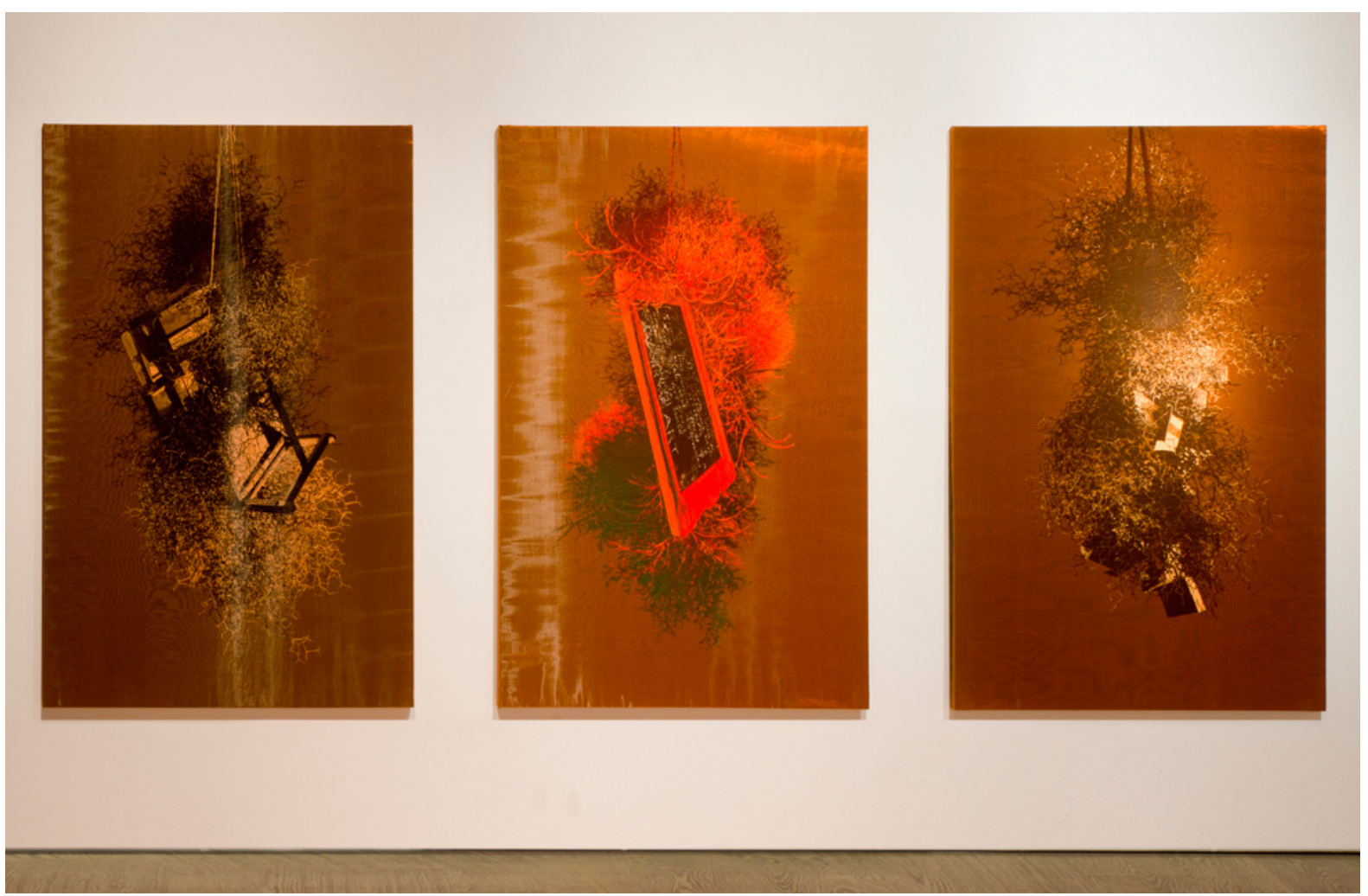

Figura 3. Javier Garcerá, “Hogueras”. 200 x 130 cm., técnica mixta sobre seda, 2017/18

\section{La obra como umbral}

Si en el apartado anterior hemos apuntado cómo el proceso de elaboración de la obra incide en la recepción de ésta por parte del espectador, quisiéramos abordar a continuación una reflexión sobre cómo la complejidad formal de las piezas pictóricas que estamos analizando fomenta una cierta inabarcabilidad de la mirada y de la comprensión.

Frente a la exhaustiva visibilidad de la imagen mediática digital, las propuestas que aquí estamos estudiando se definen por ciertos aspectos como son el sentido de lo oculto, lo inaccesible y lo enigmático. Los cuadros realizados con técnica mixta sobre seda roja que forman parte del proyecto "Ni decir" arriba mencionado ofrecen distintas imágenes según el espectador cambia su posición en el espacio (Figura 4 y 5). Así pues, dichas obras no sólo escapan a la reproducción fotográfica, sino que tampoco pueden ser atrapadas por el observador más que por un breve instante. Del mismo modo, tampoco pueden ser traducidas por el lenguaje y la teoría, pues estas herramientas impiden el acceso a la excepcionalidad inaprensible que las piezas poseen. Son obras que, a través del juego que nace de lo indefinido y de la imprecisión, ofrecen ese espacio de negatividad que Byung-Chul Han considera vital para la contemplación estética. Según el filósofo, "lo único que mantiene despierta la mirada es la alternancia rítmica de presencia y ausencia, de encubrimiento y desvelamiento" (Han, 2015, p. 18). Es justo ese balanceo entre el velar y el desvelar lo que constituye el poder de seducción de las piezas pictóricas que estamos revisando. En ellas permanece algo oculto que seduce al espectador, algo que no puede ser nombrado ni revelado pero que, sin embargo, le atrae bajo el sello del enigma. Roland Barthes denominó a ese algo como el punctum de la fotografía. Para el autor, el punctum marca un vacío en el campo visual, un campo ciego que provoca en el espectador una conmoción (Barthes, 1989). Por el contrario, lo que produce la imagen mediática digital es un agrado, no hay nada en ella que pueda punzar, que pueda herir, al observador. 


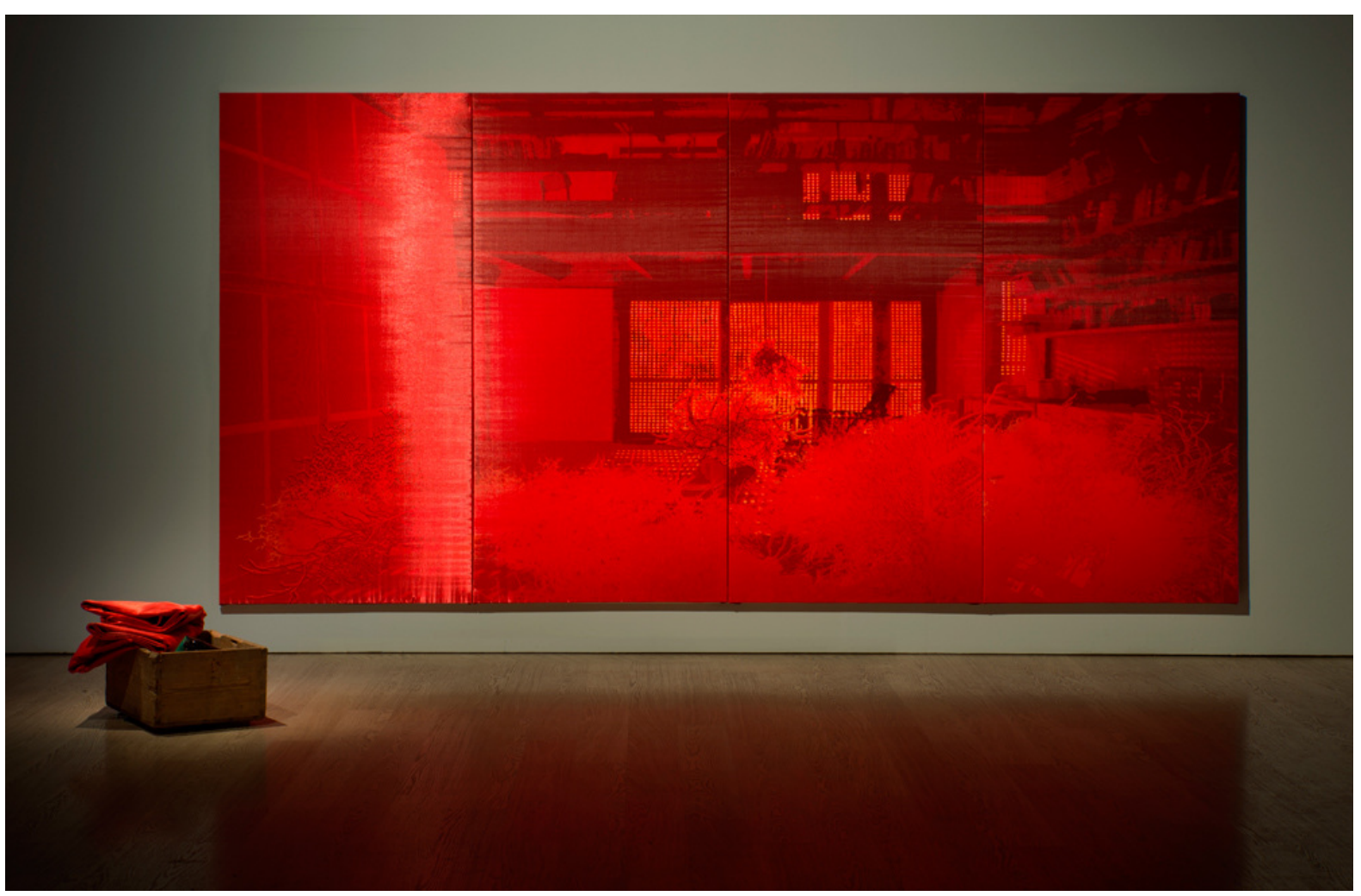

Figura 4. Javier Garcerá, “Ni decir”. 200 x 400 cm., técnica mixta sobre seda, 2018

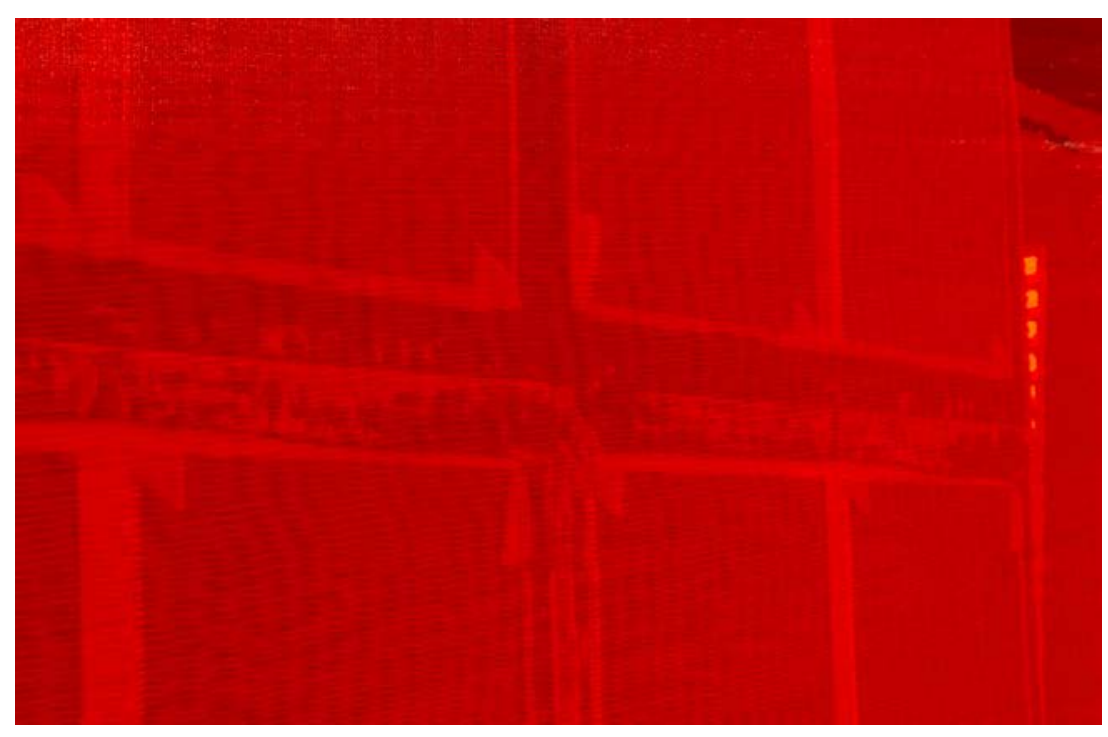

Figura 5. Javier Garcerá, “Ni decir”. 200 x 400 cm., técnica mixta sobre seda, 2018. (Detalle)

Según Byung-Chul Han, "ver, en un sentido enfático, siempre es ver de forma distinta, es decir experimentar. No se puede ver de manera distinta sin exponerse a una vulneración. Ver presupone la vulnerabilidad" (Han, 2015, p. 53). Si nos centramos en el proyecto expositivo "Ni decir", podemos considerar que esa experiencia del dejarse llevar a la que hacía referencia Peiró estaría vinculada a esa "negatividad del verse conmocionado y arrebatado, que es la negatividad de la vulneración" (Han, 2015, p. 62). En este sentido, el hecho del ver sería "un dejar que algo suceda o un exponerse a un suceso" (Han, 2015, p. 54). El sujeto debe volverse receptivo a la posibilidad del acontecimiento, a la aparición de lo inesperado. El acontecimiento es la irrupción de lo otro que desgarra al sujeto y le dirige hacia ese espacio de negatividad en el que no le es fácil reconocerse. En palabras de Gilles Deleuze, el acontecimiento "no es lo que sucede, pero está en lo que sucede" (Deleuze, 1994, p. 158). En este sentido, lo que propone el proyecto expositivo "Ni decir" es 
una invitación a que el espectador se entregue a ese universo múltiple, fascinante y aleatorio de la seducción venida de fuera al que Baudrillard haría referencia en su texto Las estrategias fatales.

Para que ese tipo de experiencia que acabamos de señalar se produzca, es necesaria una mirada contemplativa que no es más que el ejercicio de dejar que las cosas se acerquen y muevan hacia nosotros. Si anteriormente hemos señalado que la imagen mediática digital carece de toda distancia, en este caso las piezas que componen el proyecto expositivo "Ni decir" ofrecen esa distancia necesaria para la experiencia del ver. Una distancia que nos permite reconocer lo que vemos al tiempo que nos asegura que jamás tendremos acceso a un conocimiento absoluto de lo que acontece entre la obra y el sujeto. Porque la obra es un umbral interminable, un umbral absoluto ante el cual uno debe suspender todo su ser y aceptarse en una entrega que se desvanece en cada instante para volver a reaparecer si nuestra actitud sigue siendo de escucha.

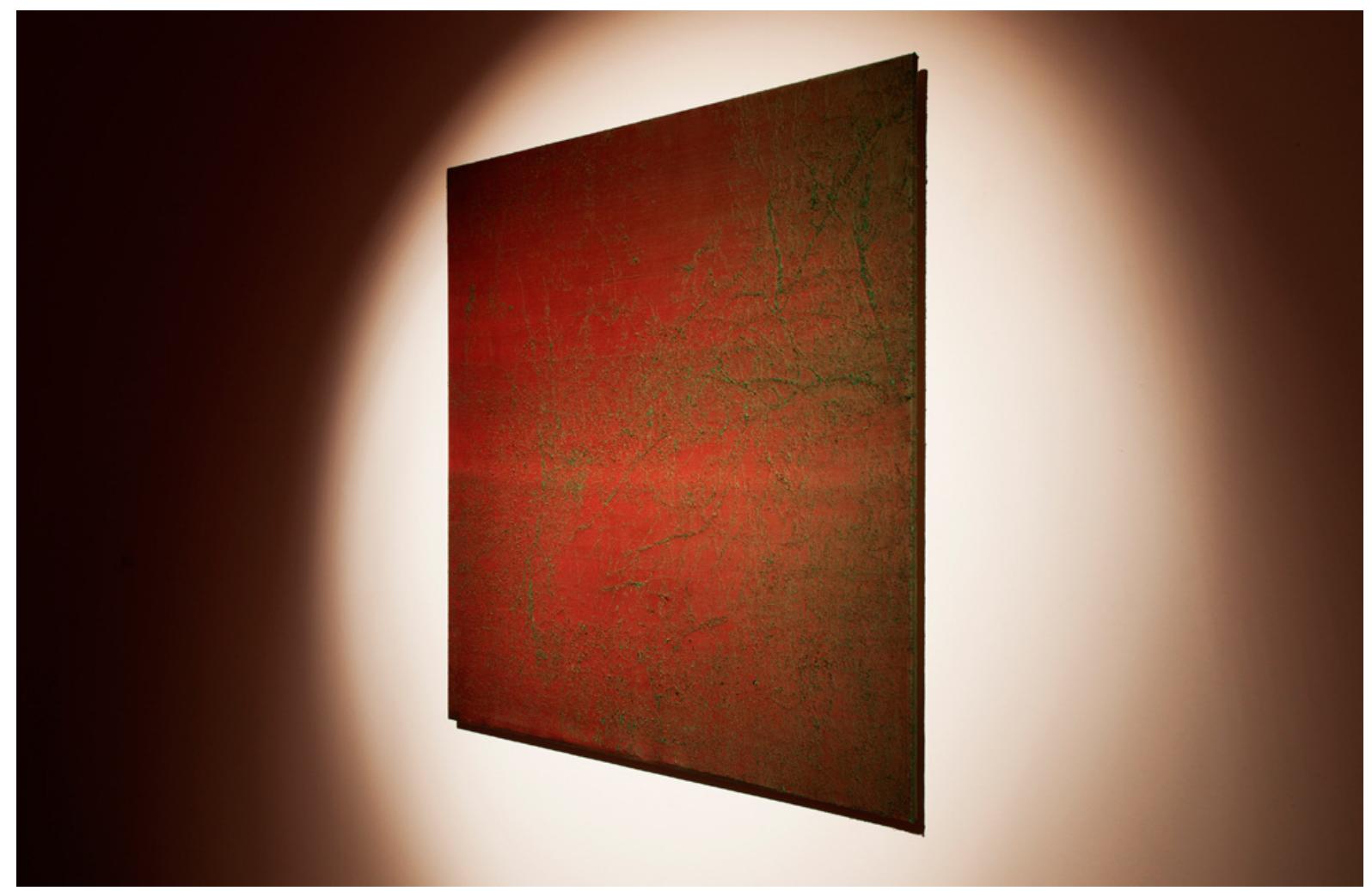

Figura 6. Javier Garcerá, "La menor distancia”. 110 x 110 cm., seda erosionada, 2017

\section{CONCLUSIONES}

Este estudio nos ha permitido defender las posibilidades expresivas del lenguaje pictórico como medio que ofrece ese espacio de negatividad que Byung-Chul Han echa en falta en la sociedad contemporánea y que considera vital para el desarrollo del conocimiento humano. Frente a esa disminución de la capacidad contemplativa y reflexiva que el filósofo observa en la sociedad, el proyecto "Ni decir" de Javier Garcerá estimula una apertura de la percepción que permite ver más allá de la representación pictórica.

Como hemos planteado, delante de sus obras la mirada del espectador permanece en una alternancia rítmica entre presencia y ausencia, encubrimiento y desvelamiento, aspectos que se relacionan con el tema de la imagen [n] visible que la presente edición del congreso ANIAV propone. Son propuestas que suscitan una tensión entre visibilidad e invisibilidad que seduce al espectador y le conduce a ese espacio de la incertidumbre, de lo imprevisible y de lo insondable. Es entonces cuando el tiempo se intensifica, como resultado de una mirada contemplativa y desinteresada que permite al sujeto mantenerse en el ritmo abierto de lo existente, en esa tensión entre el very el perder. 


\section{FUENTES REFERENCIALES}

Barthes, R. (1989). La cámara lúcida: nota sobre la fotografía (1aed.). Barcelona: Paidós.

Baudrillard, J. (1984). Las estrategias fatales (1a ed.). Barcelona: Anagrama.

Baudrillard, J. (1991). La transparencia del mal (1a ed.). Barcelona: Anagrama.

Deleuze, G. (1994). Lógica del sentido (1ae ed.). Buenos Aires: Agostini.

Garcerá, J. (2018). Ni decir. Granada: Universidad de Granada.

Han, B. (2012). La sociedad del cansancio (1a ed.). Barcelona: Herder.

Han, B. (2013). La sociedad de la transparencia (1a ed.). Barcelona: Herder.

Han, B. (2015). La salvación de lo bello (1a ed.). Barcelona: Herder.

Martínez, L. (2019, feb. 12). Byung-Chul Han: El ocio se ha convertido en un insufrible no hacer nada. El Mundo. Recuperado 15 febrero 2019, de https://www.elmundo.es/papel/lideres/2019/02/12/5c61612721efa007428b45b0.html

Simmel, J. (1927). Sociología: estudios sobre las formas de socialización. Revista de Occidente, 15 (3), 101-168.

Walter, B. (2003). La obra de arte en la época de su reproductibilidad técnica (1aed.). México: Itaca.

Walter, B. (2008). El narrador. (1a ed.). Santiago de Chile: Ediciones Metales Pesados. 